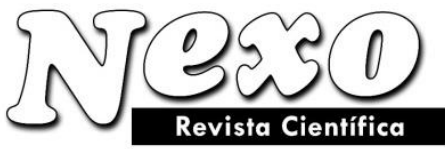

ISSN-E 1995-9516

Universidad Nacional de Ingeniería COPYRIGHT @ (UNI). TODOS LOS DERECHOS RESERVADOS http://revistas.uni.edu.ni/index.php/Nexo https://doi.org/10.5377/nexo.v34i06.13174

\title{
Simulation and predictive control of the gas transportation system in a large industrial zone
}

\section{Simulación y control predictivo del sistema de transporte de gas en una gran zona industrial}

\author{
Sergey G. Marchenko ${ }^{1,}$, Leonid I. Berner ${ }^{2}$, Yuri M. Zeldin ${ }^{2}$ \\ ${ }^{1}$ Gazprom Transgaz Moscow LLC, Moscow, Russian Federation \\ ${ }^{2}$ Atlantictransgazsystem JSC, Moscow, Russian Federation \\ *email: sergo46xxx@ mail.ru
}

(recibido/received: 18-octubre-2021; aceptado/accepted: 02-diciembre-2021)

\begin{abstract}
The article describes an approach to the operational and supervisory control of a gas transmission system for large industrial zones using a model predictive control, as well as analytical and simulation methods. The operational and supervisory control of the gas transportation system covers the time horizon from several hours to several days and involves performing several cyclically repeated actions. The authors propose a time series predictive model of the gas consumption parameter considering temperature weather conditions, which is extended based on accounting for the correlation relationships between the consumption volumes of each consumer. The control methods used today, reacting to the current deviations from the planned regime, a priori do not allow achieving the best results. A significant increase in the stability of control and a reduction in the cost of fuel and energy resources can be achieved by using the control method based on predictive models. In this case, the control object model is used to predict its behavior within the selected time horizon, and optimal control actions are selected on this basis. The process of predicting and selecting control actions is periodically repeated, constantly changing the time horizon boundaries. The described method of changing the flow diagram consists either in changing all the flows at the same time or in a preemptive and smooth transition based on the introduction of a weighted flow diagram for various stationary modes, provided that their mismatch is minimized at neighboring time intervals corresponding to the intervals of constancy of consumption requests.
\end{abstract}

Keywords: fictitious node; flow diagram; gas transportation system; operational and supervisory control; predictive model.

\section{RESUMEN}

El artículo describe un enfoque para el control operativo y de supervisión de un sistema de transmisión de gas para grandes zonas industriales utilizando un modelo de control predictivo, así como métodos analíticos y de simulación. El control operativo y de supervisión del sistema de transporte de gas cubre el horizonte temporal de varias horas a varios días e implica la realización de varias acciones cíclicamente repetidas. Los autores proponen un modelo predictivo de series de tiempo del parámetro de consumo de gas considerando las condiciones climáticas de temperatura, que se amplía con base en la contabilidad de las relaciones de correlación entre los volúmenes de consumo de cada consumidor. Los métodos de control utilizados en la actualidad, reaccionando a las desviaciones actuales del régimen planificado, a 
priori no permiten lograr los mejores resultados. Se puede lograr un aumento significativo en la estabilidad del control y una reducción en el costo del combustible y los recursos energéticos utilizando el método de control basado en modelos predictivos. En este caso, el modelo de objeto de control se utiliza para predecir su comportamiento dentro del horizonte de tiempo seleccionado, y las acciones de control óptimas se seleccionan sobre esta base. El proceso de predecir y seleccionar acciones de control se repite periódicamente, cambiando constantemente los límites del horizonte temporal. El método descrito para cambiar el diagrama de flujo consiste en cambiar todos los flujos al mismo tiempo o en una transición preventiva y suave basada en la introducción de un diagrama de flujo ponderado para varios modos estacionarios, siempre que su desajuste se minimice en intervalos de tiempo vecinos. correspondiente a los intervalos de constancia de las solicitudes de consumo.

Palabras claves: nodo ficticio; diagrama de flujo; sistema de transporte de gas; control operativo y de supervisión; modelo predictivo.

\section{INTRODUCTION}

The main goal of the gas transportation system (GTS) is the implementation of the gas delivery plan, as well as the guaranteed delivery of contract volumes of gas to consumers, while the maximum performance of the GTS should be provided at the minimum energy costs for the reporting period (Reshetnikov, 2011). The set goals must be achieved under operating restrictions (minimum and maximum pipeline pressure limits, reserve capacities of the gas compressor unit, and maximum effective velocity), as well as allow for routine maintenance and repair. For planning the GTS mode and drawing up a switching plan, mathematical models of GTS are actively used currently in the mode of variant calculations, where the current online mode is taken as the initial state (Löhr y Houben y Moser, 2020; Marchenko, 2021).

Mathematical models of non-stationary non-isothermal flow processes in pipes are well known, and their use to simulate non-stationary operating modes for systems that are simple in configuration is technically feasible (Tri Tran y Ya y Hunjet, 2020; Hassanpour y Corbett y Mhaskar, 2020; Huang y Chen, 2015). Fundamental difficulties will appear when trying to create and implement methods for optimizing nonstationary control modes for complex GTS (Vanchin, 2014; Sukharev y Samoilov, 2016). At that, the presence of variable dynamics of the consumption plan, the limited availability of resources, such as the gas amount in pipelines, the reserve of gas pumping units (GPU) capacity, and others, as well as significant unevenness of gas consumption during the day create great problems in developing optimal control actions.

\section{METHODS}

The operational management of the GTS is carried out by the operative dispatching service of the enterprise. A typical operative dispatching service of a GTS includes the following stages (Figure 1): 


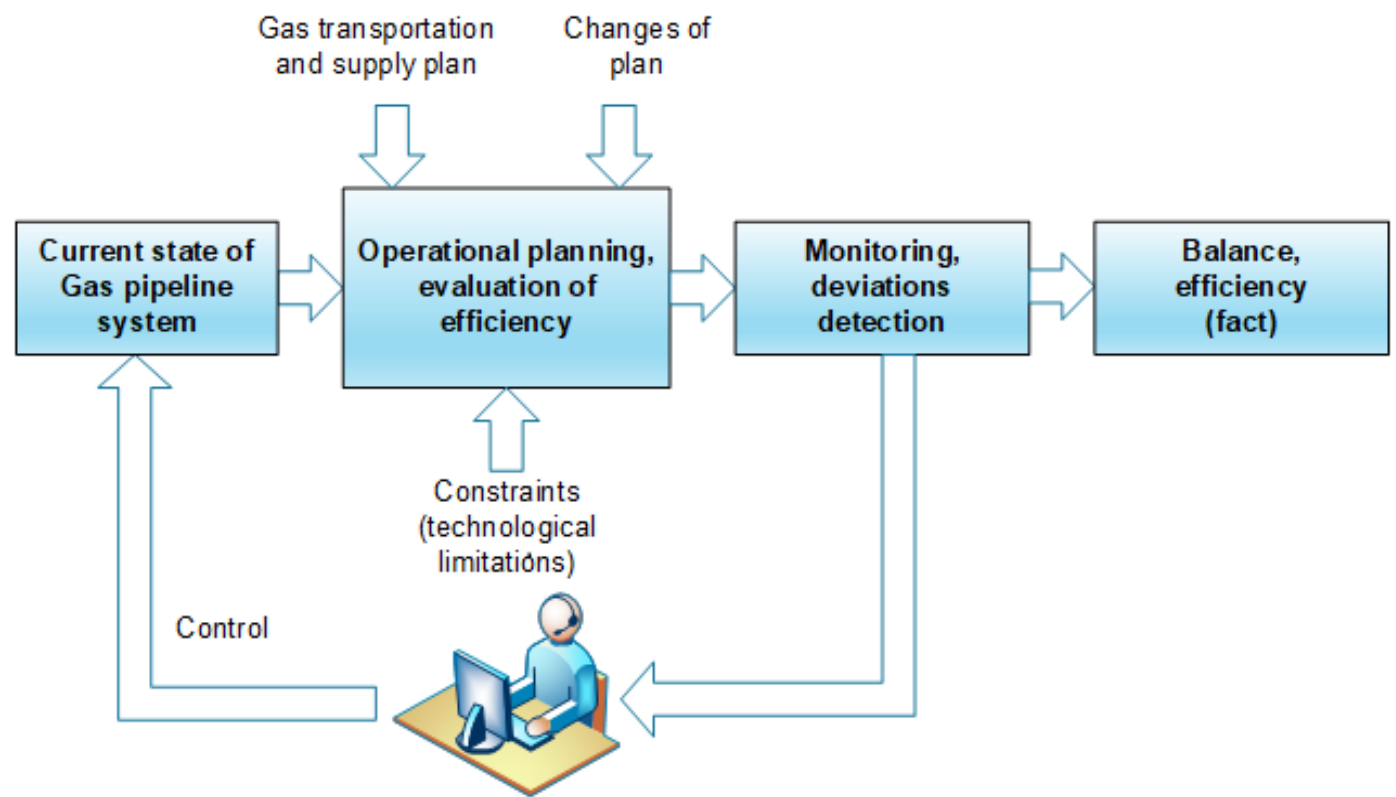

Figure 1. Operative dispatching service of a GTS

- planning of the GTS operation mode in terms of the gas supply plan, the current state of the system, planned maintenance of gas pipeline sections and technological equipment;

- setting up the GTS operation modes;

- monitoring of parameters during operation, detecting deviations from the planned modes;

- taking corrective measures to return to the planned mode (if necessary);

- taking corrective measures in case of any changes to the gas delivery plan.

Operative dispatching service covers a time horizon from several hours to several days, during which the actions described above are repeated cyclically.

We proposed a time series predictive model of the parameter considering temperature weather conditions (Marchenko et al., 2018). In this study, we proceed from the condition that there are time series of the parameter $\mathrm{Z}(\mathrm{t})$ and the external factor $\mathrm{X}(\mathrm{t})$ affecting it. The predictive time series of the gas consumption volume parameter $Z_{T+1}^{P}$ in the model is determined based on the corresponding prediction of the influencing factor $X_{T+1}^{P}$. For this purpose, a maximum similarity sample $Z_{\mathrm{kmax} *}^{M}$ is searched for a sample $Z_{T-M+1}^{M}$ containing the parameter values immediately before the prediction moment. To calculate the prediction of the parameter, a sample $Z_{k \max *+M}^{P}$ located on the time axis immediately after the maximum similarity sample is used, as well as a predictive sample of an external factor $X_{T+1}^{P}$. Calculating the prediction of the parameter involves the influence coefficients of an external factor, which are calculated from the values of the series $Z_{k m a x *}^{M}, Z_{T-M+1}^{M}, X_{T-M+1}^{M}$. The weather prediction of the Hydrometeorological Center of Russia is used as a prediction of an outdoor air temperature as an external factor (Figure 2). 


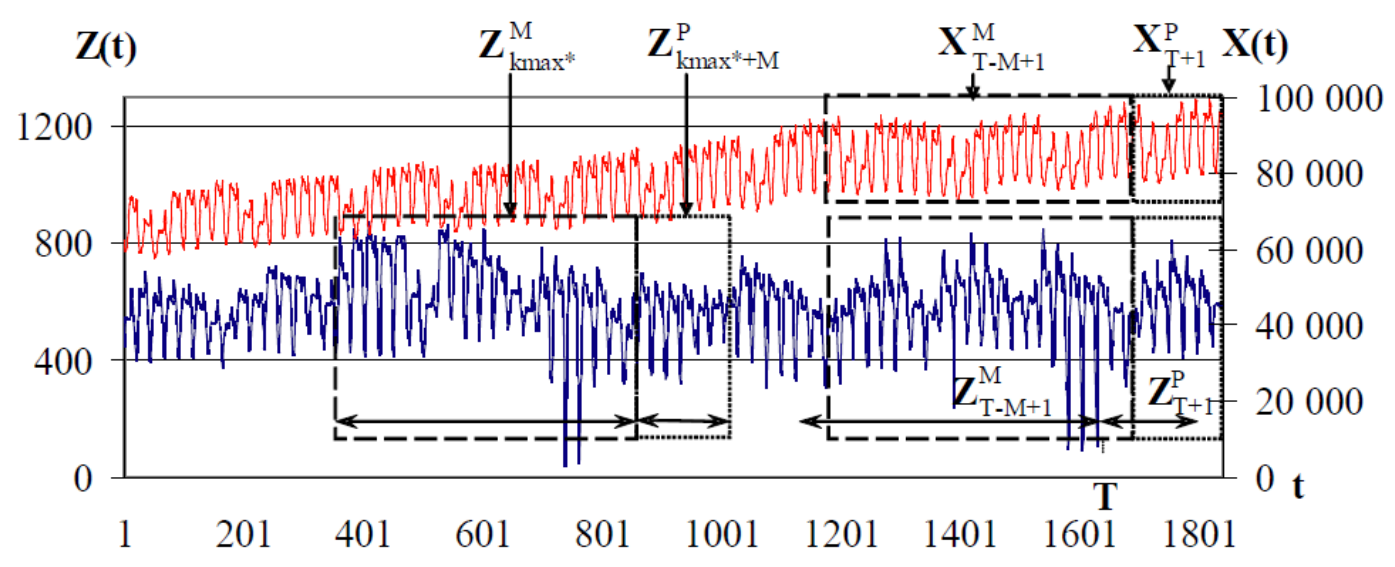

Figure 2. A sampling of the time series similarity considering the external factor

Besides, we extended the predictive model considering the correlation relationships between the volumes of each consumer. At that, at the first stage, the initial multidimensional consumption series $\left\{\mu_{i},\right\}, i-$ $1, \ldots, n$, based on the factor analysis model, is converted into a series of main components $\xi_{1}=$ $\sum_{j=1}^{p} \beta_{1 j} \mu_{j}, \ldots, \xi_{p}=\sum_{j=1}^{p} \beta_{p j} \mu_{j}$, where $\beta_{i j}$ are the conversion coefficients. Since the main components $\xi_{1}, \ldots, \xi_{p}$ are uncorrelated with each other by definition, then at the second stage, the similarity method described above was used to predict each of these time series. And at the third stage, based on the calculation of the inverse matrices, obtained at the first stage, the predictions of the main components were converted into delivery predictions for each consumer.

Thus, the input flows of the model are the time series of gas delivery plans and consumption predictions, although in general, predictive models can also be used for delivery time series.

The GTS operative dispatching service system is a closed system where a person (operator) is part of a cycle (Nasr y Connor, 2014; Mahmoudimehr y Sanaye, 2014). The GTS is a very complex control object in which the control command is worked out not instantly, but after 2-6 hours (O'malley et al. 2020). At that, the system's response depends not only on the current state but also on the system's prehistory, since the system consists of interconnected elements with significantly different response speeds (for example, a long large-diameter pipeline with a compressor station and a short pipeline leg for a large consumer). This factor plays an important role for large industrial zones, which are also characterized by irregular gas consumption, the availability of limited resources, technological limitations, and changes in the characteristics of GTS during maintenance or repair. Achieving the best indicators at a specific time point can lead to further excessive energy consumption and loss of efficiency of the entire system during the entire planning period (Juanwei et al. 2019; Xiao et al. 2021). That is why the control methods, used today, when responding to current deviations from the planned regime, a priori do not allow achieving the best results (Chaczykowski y Zarodkiewicz, 2017; Seleznev y Aleshin y Pryalov, 2007). A significant increase in the stability of control and reduction in the cost of fuel and energy resources can be achieved by using the control method based on predictive models. In this case, the model of the control object is used to predict its behavior within the selected time horizon, and optimal control actions are selected on this basis. The prediction process and selecting control actions are periodically repeated, constantly changing the time horizon boundaries. The described method allowed using the resources of the system to increase its sustainability and/or energy efficiency. The increase in energy efficiency was also achieved by analyzing the behavior of the system over a certain period and making decisions that ensure integrated energy efficiency over the entire time interval, rather than instantaneous improvement (Wang et al. 2020). 
At each moment, the control is an arbitrary flow diagram $F=\left(q_{1}, q_{2}, \ldots, q_{|E|}\right)$, and the control process is defined as a sequence of flow diagrams $F^{(1)}, F^{(2)}, \ldots, F^{(K)}$, which is selected from certain considerations of optimizing the GTS functioning process.

In addition to the calculated gas flow ratios in the pipeline, forming interface models of capacity and offtake/delivery constraints a model of a gas transmission is required including a model of a compressor station (Vanchin, 2014). Since the compressor station (CS), as a control element, is one of the key links of the GTS, a model of the compressor station has been developed as well. The energy supply to the gas flow at the CS, mainly corresponding to the change in the potential energy of the pressure, is determined from the thermodynamic relation $W=\int_{v_{1}}^{v_{2}} P d v$, from which theoretical dependences for the useful internal power are obtained, which, considering the efficiency of the compressor, can be written as follows: assuming a polytropic compression, $N_{\text {пол. }}=A_{N} \frac{m}{m-1} \frac{P_{\mathrm{Bx}} Q_{\mathrm{Bx}}}{\eta}\left[\varepsilon^{\frac{m-1}{m}}-1\right]$, assuming an isothermal compression $N_{\text {изот. }}=A_{N} \frac{m}{m-1} \frac{P_{\mathrm{BX}} Q_{\mathrm{Bx}}}{\eta} \ln \varepsilon$, where $\mathrm{A}_{\mathrm{N}}$ is the coefficient to bring into compliance dimensions of physical quantities; $m$ is the polytropic index for natural gas in conditions of its long-distance transportation, $m \approx 1,3-1,37 ; P_{\mathrm{BX}}$ is initial pressure or inlet pressure; $Q_{\mathrm{BX}}$ is the volume productivity at the inlet; $\varepsilon=\frac{\mathrm{P}_{\mathrm{H}}}{\mathrm{P}_{\mathrm{BX}}}-$ is the compressor pressure ratio; $\mathrm{P}_{\mathrm{H}}$ is the discharge pressure.

The reduced internal specific power is represented in the form of a polynomial of the second degree $N_{i}=$ $b_{0}+b_{1} Q+b_{2} Q^{2}, b_{0}=N_{0}-b_{1} Q_{0}-b_{2} Q_{1}^{2}, b_{1}=\frac{N_{0}-N_{2}}{Q_{0}-Q_{2}}-b_{2}\left(Q_{0}+Q_{2}\right)$, where $Q_{0}, Q_{1}, Q_{2}$ are arbitrarily selected volumetric flow rates; $N_{0}, N_{1}, N_{2}$ are the corresponding values of the internal specific power found by the universal characteristic.

The control procedure itself consisted in calculating the node flow rates $Q(t)\left(\forall t, t^{*} \in T_{k}, Q(t)=Q\left(t^{*}\right)\right)$ for each interval of constancy $T_{k}=\left[T_{b k}, T_{e k}\right]$, in which $\forall j, t 1 \in\left[T_{b k}, T_{e k}\right], t 2 \in\left[T_{b k}, T_{e k}\right]$ is valid both for the stationary mode and the sequential transition between the calculated flow diagrams at specified time points. The flow diagram $q(k)$ is formed considering the current state $M(t)$ after the implementation of the previous flow diagram $q(k-1)$, considering compliance or non-compliance with the balance. In case of non-compliance with the balance, and consumption exceeds deliveries, it is assumed that the gas reserves available in the pipe sections will be used. If deliveries exceed consumption, then all pipe sections are represented as additional sinks in which gas reserves are accumulated in compliance with technological restrictions. The transition between flow diagrams, depending on the selected control criterion, can be carried out by a one-time change of all flows, or with a proactive and smooth transition based on the introduction of a weighted flow diagram for various stationary modes, proceeding from on minimizing their mismatch at neighboring time intervals corresponding to the intervals of constancy of consumption requests.

In this study, we proceeded from the need to solve the following problem. Let $F S_{1}$ and $F S_{2}$ be two stationary flow diagrams, then the weighted flow diagram will be set based on the relation $F S(t)=$ $\alpha(t) F S_{1}+\left(1-\alpha(t) F S_{2}\right)$, where $\alpha(t)$ is a time function monotonically decreasing from 1 to 0 . To calculate fictitious flow diagrams, it is proposed to introduce the incidence matrices of the graphic representations of the fictitious source diagram $G r^{f i}$ and the fictitious sink diagram $G r^{f s}$, which are an extension of the original GTS graphic representation. Graph of a fictitious source diagram $G r^{f i}=$ $\left(G^{f i}, E^{f i}\right.$ has many vertices $G r^{f i}=G \cup G^{f}$ and many arcs (Fig. 3 a). One arc from $E_{i}^{f} \in E^{f}$ and one vertex from $G_{i}^{f} \in G^{f}$ will correspond to each $\operatorname{arc} E_{i} \in E$ of the original graph $G$. Thus, $\operatorname{card} G^{f}=\operatorname{card}^{f}=$ $\operatorname{card} E$ and the incidence matrix of the fictitious source diagram $G r^{f i}$ will have a dimension of $(|G|+$ $|E|) *(2 *|E|)$. 
The matrix itself $A^{f i}=\left\|\begin{array}{cc}A & A^{*} \\ 0 & I\end{array}\right\|$, where $A^{*}=\frac{1}{2}(a b s(A)-A), a b s\left\|a_{i j}\right\|=\left\|\left|a_{i j}\right|\right\|$, and $I_{|E|}$ is the unit matrix. The set of vertices and the set of arcs of the graph of a fictitious stock diagram $G r^{f s}=\left(G^{f s}, E^{f s}\right.$ (Fig 3 b) will coincide with the corresponding elements of the graph $G r^{f i}=\left(G^{f i}, E^{f i}\right)$. The dimensions of the incidence matrices will also coincide. At that, the very matrix $A^{f s}=\left\|\begin{array}{cc}A & A^{* *} \\ 0 & -I\end{array}\right\|$, where $A^{* *}=$ $\frac{1}{2}(\operatorname{abs}(A)+A)$.

a) the diagram of source vertices

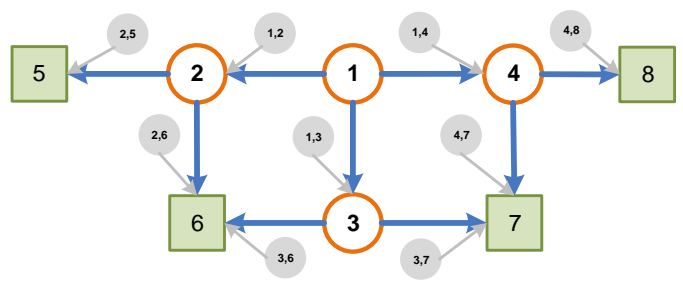

b) the diagram of sinks

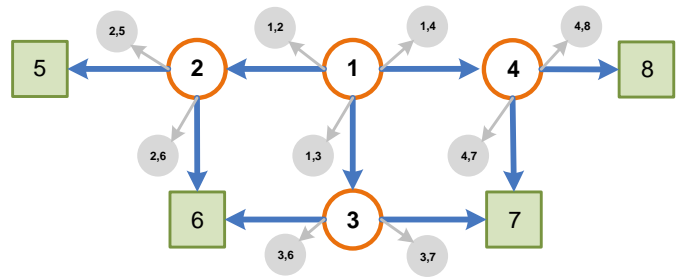

Figure 3. Formation of fictitious sources vertices and sinks

Moreover, for diagrams with fictitious vertices, the maximum implementation time was calculated, which is associated with the limited mass of gas in each pipe section. To increase this time, the criterion of the minimum imbalance between the delivery subnets of each consumer is added to the minimum mismatch criterion. The calculation of the time when implementing the fictitious sink diagram is performed based on the selected values of the maximum pressure in the gas pipeline, while for the sources - based on the minimum pressure.

\section{RESULTS}

The control method based on the predictive model is currently being increasingly used in GTS operational dispatch control systems (Azadeh et al. 2016). However, the maximum effect of its use can be reached only by achieving high accuracy of the prediction. To do this, the predictive model must constantly receive information from the SCADA system and make a prediction considering the actual parameters and parameters, corresponding to the previous state. To ensure high accuracy of prediction, it is necessary not only to use an adequate mathematical model of the GTS but also to ensure guaranteed reliability of the actual parameters (considering their number which can reach several thousand). In a real system, due to sensor failures, lack of communication, etc., some of the actual parameters are constantly unreliable. To obtain high accuracy of mathematical simulation, it is necessary to perform data cleaning, that is, preprocessing the actual data, discarding unreliable values. To further improve the accuracy of prediction, it is necessary to take into account the daily unevenness of gas consumption, for which appropriate algorithms and software systems are being developed. However, the problem of the behavior of the mathematical model of the GTS when predicting technological constraints, as well as presenting the prediction results to the operator, has not yet been investigated sufficiently (Marchenko et al. 2020). The GTS is the most complex control object, with a set of target parameters and possible control actions that are applied at different times (within the prediction horizon). The control strategy is determined by the operator based on knowledge and experience. Therefore, the form of presenting the results of GTS behavior prediction to the operator is of paramount importance.

During the calculation of the GTS control system's behavior prediction, a situation may arise when, due to the achievement of technological restrictions, it is impossible to provide the specified boundary conditions for the input/output data of the gas delivery system. For example, due to the minimum allowable pressures on a certain pipe section, it is impossible to ensure the projected gas consumption through this section (Tri Tran y Ya y Hunjet, 2020). Such a situation can potentially occur in the gas delivery system of a large 
industrial zone under peak load conditions. Usually, in this case, the GTS model signals the impossibility of further calculations. Such behavior of the model is unsuitable for predictive model based control since the operator receives a signal indicating the problem, rather than the way to solve it.

When the technological limitations are reached, the GTS model, operating in the prediction mode, should continue the calculation. This is possible by changing the boundary conditions or using brute-force search methods. The following rules should be laid down in the GTS model:

- at a given gas flow velocity at the boundary and the design pressure, when the minimum or maximum allowable pressure is reached, the model should proceed with the calculation at a fixed pressure and flow velocity. When the pressure returns to the permissible range, it is necessary to return to the calculation with the given flow rate and pressure;

- when the operating point of the compressor station goes beyond the permissible modes, the model should change the dynamics in such a way that the operating point remains within the permissible range;

- when the maximum (minimum) velocity of the gas pumping unit is reached, then the model should start automatically the additional gas pumping unit or stop the operating one.

The model must notify the operator of any automatic changes in the boundary conditions and operating modes of the equipment. This type of prediction will allow assessing the scale of a potential problem in terms of scope and time, taking the necessary measures to eliminate it (including limiting gas deliveries to consumers, as a last resort). A typical method of presenting prediction results is to present parameters' (pressure, flow, temperature) trends at key points. However, they do not allow assessing the overall picture of the GTS behavior in general, especially with a large number of consumers, and do not allow assessing the difference between the planned and possible consumption of the particular object (upon reaching technological restrictions).

When visualizing the prediction results, it is proposed to use color solutions, where the color of the pipeline at the current point corresponds to a certain pressure (yellow - indicating high pressure, green medium, and blue - low pressure), while the size of the arrow should correspond to the flow rate level. The color of the consumers may reflect the difference between the planned and possible hourly gas consumption in absolute units or \% of the planned value (green - the planned volume of gas, red - when providing the planned volume is impossible (from light to dark red, depending on the $\%$ of the smallest delivery) (Figure 4).

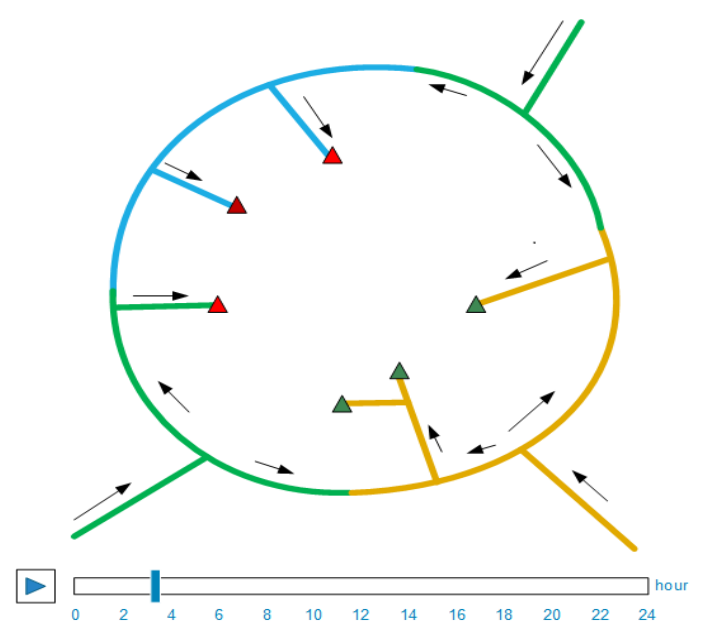

Figure 4. Display of prediction results (example) 
Since the main purpose of the gas supply system is to ensure guaranteed gas supply to consumers, this information will allow the dispatcher to develop the most effective and applicable control strategy.

For the data generated according to the consumers' requests, which are non-stationary, based on the proposed approach, considering the formation of a sequence of flow diagrams based on minimizing their mismatch, simulation was carried out which, as was shown, is compliant with statistical data. It is also shown that as a result of the application of such a procedure, a significant reduction of disparities in gas supply was obtained.

\section{DISCUSSIONS}

Thus, the model predictive control can increase the efficiency of the operational and supervisory control of the GTS. However, to fully realize the potential of the method, it is necessary to correct the operation of the mathematical model of the GTS and present the calculation results in an operator-friendly form.

Our original approach to form a GTS subnet for a specific consumer and to estimate the maximum flows for all consumers with pressure variations in all piping assemblies, which is based on transiting from the flow diagram under consideration to the most actual one, sets the GTS controlling procedure in a nonstationary consumption mode. Simulating the dynamics of gas delivery volumes and consumption plans made it possible to assess the state of the GTS by residual gas masses in pipe sections according to the selected flow diagram. A dynamic flow control procedure has been developed in the framework of the optimization management model of non-stationary consumption modes, which is represented as a sequence of transitions between stationary flow diagrams based on minimizing their mismatch at neighboring time intervals corresponding to the intervals of constancy of consumption requests, which allows reducing further the energy inputs to change the flow diagram.

The implementation of comprehensive automation and the creation of a multi-level automated control system provides significant support to operational and technical personnel when solving the problems of operating complex process equipment. Automated situation analysis and decision support tools reduce the number of possible errors and the influence of the human factor on the complex equipment control in nonstationary conditions, especially in non-routine events and in emergencies. A significant effect can be achieved through the use of control optimization methods and models included in the general decision support system, as well as the operational exchange of dispatching information between all control levels.

\section{CONCLUSION}

The results of the simulation of the proposed approach based on the initial data from gas consumers of a large industrial zone are presented. It is shown that forming a sequence of flow diagrams based on the principle of minimizing their mismatch allows reducing further the energy input to change the flow diagram. Using a model predictive control allows reducing the number of errors, and increasing energy efficiency. It is concluded that it is necessary to continue working towards the development of control optimization methods and models included in the general decision support system.

\section{REFERENCES}

Azadeh, A., Gaeini, A., Motevali Haghighi, S., Nasirian, B. (2016). A unique adaptive neuro-fuzzy inference system for the optimum decision-making process in a natural gas transmission unit. Journal of Natural Gas Science and Engineering, 34(7), 472-485. Available at: http://dx.doi.org/10.1016/j.jngse.2016.06.053 
Chaczykowski, M., Zarodkiewicz, P. (2017). Simulation of natural gas quality distribution for pipeline systems. Energy, 134, 681-698. Available at: https://doi.org/10.1016/j.energy.2017.06.020

Hassanpour, H., Corbett, B., Mhaskar, P. (2020). Integrating dynamic neural network models with principal component analysis for adaptive model predictive control. Chemical Engineering Research and Design, 161, 26-37. Available at: https://doi.org/10.1016/j.cherd.2020.03.031

Huang, H., Chen, L. (2015). A hybrid model predictive control diagram for energy and cost savings in commercial buildings: Simulation and experiment. In: 2015 American Control Conference, Chicago, IL, USA, July 1-3, 2015. IEEE, pp. 256-261. http://dx.doi.org/10.1109/ACC.2015.7170745

Juanwei, Ch., Tao, Y., Yue, X., Xiaohua, Ch., Bo, Y., Baomin, Zh. (2019). Fast analytical method for reliability evaluation of electricity-gas integrated energy system considering dispatch strategies. Applied Energy, 242(5), 260-272. Available at: https://doi.org/10.1016/j.apenergy.2019.03.106

Löhr, L., Houben, R., Moser, A. (2020). Optimal power and gas flow for large-scale transmission systems. Electric Power Systems Research, 189(12), 106724. Available at: https://doi.org/10.1016/j.epsr.2020.106724

Mahmoudimehr, J., Sanaye, S. (2014). Minimization of fuel consumption of natural gas compressor stations with similar and dissimilar turbo-compressor units. Journal of Energy Engineering, 140(1), 04013001. Available at: https://doi.org/10.1061/(ASCE)EY.1943-7897.0000129

Marchenko, S.G. (2021). Modeling and optimization of gas transmission system control in non-stationary consumption modes. Automation in Industry, 4, 52-57. https://doi.org/10.25728/avtprom.2021.04.11

Marchenko, S.G., Berner, L.I., Zeldin, Yu.M., Khadeev, A.S. (2020). Artificial intelligence technologies in gas transmission dispatch control systems. Automation in Industry, 12, 46-49.

Marchenko, S.G., Nikanorov, V.V., Berner, L.I., Zeldin, Yu.M. (2018). Artificial intelligence methods in gas transmission system control problems. Information Technologies in Science, Education, and Management, 2(16), 18-22. http://dx.doi.org/10.47501/ITNOU.2020.2.18-22

Nasr, G.G., Connor, N.E. Natural gas engineering and safety challenges. Cham: Springer, 2014. https://doi.org/10.1007/978-3-319-08948-5

O'malley, C., Delikaraoglou, S., Roald, L., Hug, G. (2020). Natural gas system dispatch accounting for electricity side flexibility. Electric Power Systems Research, 178(3), 106038. Available at: http://dx.doi.org/10.1016/j.epsr.2019.106038

Reshetnikov, I.S. (2011). Automation of production activities of a gas transportation company. Moscow: NPP "Neftegazsoftservis".

Seleznev, V.E., Aleshin, V.V., Pryalov, S.N. (2007). Mathematical modeling of pipeline networks and channel systems: Methods, models, and algorithms. Moscow: MAKS Press.

Sukharev, M.G., Samoilov, R.V. (2016). Analysis and management of stationary and non-stationary modes of gas transport. Moscow: Publishing Center of Gubkin Russian State University of Oil and Gas (NIU). 
Tri Tran, A., Ya, Q.P., Hunjet, R. (2020). Reliability enhancement with dependable model predictive control. ISA Transactions, 106, 152-170. Available at: https://doi.org/10.1016/j.isatra.2020.06.027

Vanchin, A.G. (2014). Determining the boundaries of the application of stationary and non-stationary models of gas pipeline operation. Oil and Gas Business, 1, 598-617. http://dx.doi.org/10.17122/ogbus$\underline{2014-1-598-617}$

Wang, W., Zhang, Y., Li, Y.X., Liu, Ch; Han, Sh. (2020). Vulnerability analysis of a natural gas pipeline network based on network flow. International Journal of Pressure Vessels and Piping, 188, 104236. Available at: https://doi.org/10.1016/j.ijpvp.2020.104236

Xiao, J., Song, Ch., Zu, G., Lv, L., She, B., Zhang, X. (2021). Gas transmission capability curve of the natural gas system: Concept and steady-state model. Journal of Natural Gas Science and Engineering, 87(3), 103754. Available at: https://doi.org/10.1016/j.jngse.2020.103754 